\title{
A ASSISTENCIA À INFÂNCIA DESAMPARADA E A SANTA CASA DE SÃO PAULO: A RODA DOS EXPOSTOS NO SÉCULO XIX.
}

\section{LAIMA MESGRAVIS}

Disciplina: História do Brasil.

\section{1. - A EVOLUÇÃO DO PROBLEMA DOS ENJEITADOS NA EUROPA.}

Das mais crueis e dramáticas foi sempre, em todas épocas, a situação das crianças indesejáveis. Se os povos primitivos resolviam o problema com o infanticídio do recem-nascido, outros mais "civilizados", como os romanos, recorreram ao abandono ou à sua venda como escravo (1).

O triunfo do Cristianismo se, por um lado impôs, através de seus valores éticos, a preservação da vida como dever sagrado, por outro, ao enrijecer os padrões morais da família, com a severa condenação do adultério, especialmente da mulher, lançou a mancha do pecado sobre as vítimas dos deslizes inevitáveis. Isto fica bem evidenciado na inaptidão fundamental de um bastardo para o exercício do sacerdócio, conforme rezavam os cânones da Igreja.

Apesar disso, foi o Cristianismo o primeiro sistema religioso-filosófico que, através da pressão da Igreja, procurou desenvolver uma profunda consciência social de responsabilidade para com os desvalidos, e, entre eles, os expostos ou enjeitados (2).

$\mathrm{Na}$ Europa da Alta Idade Média rarefeita de homens, interesava tanto aos senhores feudais quanto aos camponeses e servos o recolhimento e a criação de expostos. Para os primeiros eles representariam soldados fieis para as intermináveis guerras desse mundo violento e

(1). - Neyron (R. P. Gustave), Histoire de la Charité. Editions Spes, Paris, 1927, pgs. 23 e 27.

(2). - Op. cit., acima, pág. 62. 
inseguro, enquanto para os camponeses seriam mais braços para divisão e alívio das tarefas da servidão. Os enjeitados excedentes, não absorvidos pelos feudos, encontravam abrigo nos mosteiros que os recolhiam e criavam. Desta maneira a Alta Idade Média, com seus feudos dispersos e fechados, com poucos e pequenos núcleos urbanos, não exigiu instituições especializadas e, relativamente grandes, para solucionar o problema da infância dsamparada.

Foi a urbanização, cada vez mais acelerada, da Baixa Idade Média que obrigou os habitantes das cidades a se organizarem em confrarias, irmandades e corporações para solução dos problemas sociais que antes eram resolvidos em termos pessoais. E que os laços sociais que uniam senhores e servos se implicavam em exploração da força de trabalho dos mais fracos, tambem lhes proporcionava certa proteção. O problema dos enjeitados, que é o que nos interessa no momento, agravou-se com a urbanização, porque, alem do seu natural aumento, com a concentração da população, com a diminuição do controle moral e social do comportamento de seus membros, menos sujeitos à crítica de parentes e vizinhos nas aldeias, não existiam mais grupos direta e pessoalmente interessados na sua preservação. Para o rico mercador o prestígio se traduzia em termos de ostentação de luxo e não na força das armas. A força de trabalho ele a encontrava nos artífices organizados em corporações que regulamentavam as relações entre a produção e o consumo. Como a segurança de todos estava garantida pela força coletiva das cidades não havia necessidade de exércitos particulares desaparecendo a utilidade dos agregados. Somente a evolução do espírito capitalista em paises, como a Inglaterra, desde o século XV, inspirou na burguesia a idéia da utilização do contingente humano representado pelos enjeitados e orfãos, como mão-de-obra barata e submissa, pela sua fragilidade e desvinculação das corporações, através da criação das poor-houses e work-shops.

Muito antes foi preciso que se criassem instituições de assistência aos expostos e é natural que elas surgissem sob a égide da Igreja e nas formas comunitárias do espírito medieval.

Desde o século IX a Europa, começando pela Itália (3), assistiu à criação de inúmeras instituições de amparo à infância desamparada mantidas por particulares, corporações e confrarias (4).

Se a partir de um certo momento de suas vidas o destino de orfãos se confunde com o dos enjeitados, partilhando ambos o mesmo tratamento, a verdade é que de início a sorte dos segundos é mais ingrata e

(3). - Op. cit., acima, pág. 95.

(4). - Correia (Fernando da Silva), Origens e Formação das Misericórdias Portuguesas, Lisboa; 1944, pág. 203. 
sensibilizante. Alem do abandono à porta de particulares caridosos ou nas naves de Igrejas, muitas crianças ficavam nas ruas à mercê das intempéries e dos animais, onde as deixavam mães desesperadas ou parteiras irresponsáveis.

Foi o terrivel espetáculo de crianças mortas de fome e de frio, ou devoradas por cães ou porcos que inspirou aos governos das cidades à idéia da criação da "roda".

A "roda" era um aparelho mecânico formado por um cilindro, fechado por um dos lados, que girava em torno de um eixo, e ficava incrustado nos muros dos conventos, por onde frades ou freiras recebiam cartas, alimentos ou remédios, e onde há muito, era costume colocarem-se crianças enjeitadas. Foi devido a relativa proteção que proporcionava à criança contra os perigos já mencionados e a preservação do anonimato, obviamente desejado por quem as abandonava, que as "rodas" foram adotadas nas cidades.

Depois de recolhidas nas "rodas" as crianças recebiam os mais variados destinos conforme o sistema adotado na localidade em questão. O mais comum parece ter sido a entrega à amas que as aleitavam, estipendiadas pelas paróquias ou municipalidades. Mais tarde ficavam sob a responsabilidade de particulares que se propunham a sustenta-las e ensinar-lhes um ofício. A administração da "roda", a escolha das amas e dos criadores dos enjeitados, assim como dos asilos, que completavam esse sistema de amparo à infância, era geralmente confiada pelas cidades à confrarias, mediante o pagamento de uma quota anual.

Em Portugal foi adotado o sistema descrito, embora a primeira "roda" tenha sido instalado em Lisboa em meados do século XVII, o que não impede que as municipalidades já tivessem a responsabilidade de amparar os expostos conforme regiam as Ordenações. Desde épocas remotas do reino português existiam orfanatos e asilos em muitas localidades que recebiam a proteção real.

A "Roda" de Lisboa foi entregue à administração da Misericórdia que já recolhia em seu hospital muitos expostos, sem que a Câmara da cidade contribuisse para a sua manutenção (5). A partir de 1637 a Câmara de Lisboa passou a contribuir com $689 \$ 360$ por ano para os expostos da cidade.

(5). - Peres (Damião) (dir. de), História de Portugal. Edição monumental comemorativa do $8^{\circ}$ centenário da fundação da Nacionalidade. Portucalense Editora Ltda. Barcelos, MCMXXXII. Vol. IV, pág. 568 e vol. V, pág. 470 . 


\section{2. - A SOCIEDADE COLONIAL NO BRASIL E O PROBLEMA DOS ENJEITADOS.}

No Brasil as primeiras referências aos expostos são do século XVII embora as "rodas" só tenham sido instaladas em Salvador em data incerta, mas anterior a 1700, e no Rio de Janeiro em 1738.

O fato das primeiras "rodas" terem sido instaladas em Salvador e no Rio de Janeiro vem confirmar o seu carater urbano, uma vez que, até o século XVIII, apenas essas duas localidades mereciam verdadeiramente o nome de cidade, enquanto as outras permaneciam na condição mais próxima de grandes aldeias, dominadas pelo particularismo dos "homens-bons" com os interesses voltados para suas grandes propriedades rurais, sem real preocupação com os problemas públicos (6).

E preciso recordar aqui o carater do povoamento da colônia que se fez sob o signo da lavoura tropical com base na grande propriedade onde se cristalizou a sociedade colonial. Esta se baseava na grande massa de escravos dominada por uma minoria de senhores privilegiados social e politicamente, com uma camada intermediária de homens livres, não proprietários, sem posição definida. No campo a pequena camada de homens livres vivia sob o domínio dos grandes proprietários, como "agregados" ou pequenos lavradores ou "rendeiros", mas todos ligados por relações de tipo "feudalizante", no que se refere às obrigações de cada um para com o "senhor".

$\mathrm{O}$ grande poder dos latifundiários no Brasil Colônia, deve-se, alem da sua força econômica, aos direitos políticos que receberam como "Homens-bons", e aos privilégios militares como comandantes das forças locais de defesa, ataque e polícia. A defesa da colônia contra piratas, corsários, invasores estrangeiros e índios hostis ficou basicamente, desde início, confiada aos particulares, donatários e sesmeiros, aos quais se exigia a manutenção de certo número de homens de armas para a guerra.

O latifundiário, senhor de engenho ou fazendeiro de gado, foi, assim, estimulado a manter um grande número de agregados ou dependentes de algum tipo, reproduzindo entre eles um relacionamento semelhante ao da sociedade feudal, complicado pela existência da escravidão.

E evidente que nessa sociedade patriarcal e "feudalizante" havia possibilidade para a absorção dos inúmeros bastardos e expostos ori-

(6) - Oliveira Viana, Instituições Politicas Brasileiras. Livraria José Olímpio Editora. Rio de Janeiro. 1949, cita na pág. 139 a opinião de Simão de Vasconcelos a respeito:... "De onde nasce que nenhum homem nesta terra é repúblico, nem vela ou trata do bem comum, senão cada um do bem particular. Pois o que é fontes, pontes, caminhos e outras coisas públicas, é uma piedade, porque atendo-se uns aos outros, nenhum as faz,...". 
ginados pela exploração sexual da mulher índia e negra pelo senhor branco ou pela instabilidade da vida familiar dos agregados e moradores (7) . Nos engenhos do Nordeste o exposto ali criado, assumia na idade adulta, a condição de agregado, para a realização de algumas tarefas que não podiam ser confiadas a escravos ou como força para-militar.

Apesar da falta de melhores informações, acreditamos que, em São Paulo, a condição do agregado variou de acordo com as transformações sofridas pela capitania, muito mais acentuadas do que no Nordeste.

Durante o bandeirismo, época em que não revela a documentação a menor referência a expostos mas muitas a bastardos, o problema era com certeza solucionado dentro da família patriarcal, com a absorção desses elementos para integrarem o contingente das bandeiras, absorvedoras de homens, ou para trabalharem nas pequenas lavouras de subsistência dos grandes bandeirantes.

O prestígio dos banderiantes não se media, como no Nordeste, pelas grandes propriedades ou pelo número de escravos mas pela quantidade de "arcos" que o seguiam. Nessa sociedade militarizada o exposto encontrava lugar semelhante ao que ocuparia no feudo medieval, como participante na empresa sertanista (8). No século XVIII, extintas as bandeiras, a capitania empobrecida, a dispersão da população emigrada para as minas, passaram seus habitantes a se dedicar à lavoura de subsistência, quando não ao comércio de tropas de mulas e de boiadas.

E nessas pequenas ou médias propriedades, exploradas com o trabalho da família do proprietário e seus agregados que, encontramos pela primeira vez menção constante dos expostos (9).

Os expostos, cada vez mais numerosos, durante o século XVIII, substituiam o trabalho dos índios, quase extintos, e dos negros, muito caros para a capitania que pouco produzia para exportação.

(7). - Duarte (Nestor), A Ordem Privada e a organização politica nacional. Companhia Editora Nacional. São Paulo, 1939, págs. 166-167.

(8). - Holanda (Sérgio Buarque de), Movimentos da População em São Paulo no século XVII, separata $\mathrm{n}^{\circ} 1$ da Revista do Instituto de Estudos Brasileiros. São Paulo, 1966, pág. 79. - "Em outras palavras ainda que feita de gente inconstante, infiel, ociosa, frequentemente indômita, como se dizia, pode ter sua função social definida e que. não se pode facilmente suprir" e pág. 80 . - "E dela, em grande parte, que se valem particulares e governantes na luta contra o gentio e o castelhano".

(9). - Hermann (Lucilla), Evolução da Estrutura Social de Guaratinguetá num período de trezentos anos, in "Revista de Administração" no 5-6, págs. 28 e 34 . Levantamento de 1775 . 
A absorção natural dos expostos no meio rural explica o fato de não serem mencionados como problema social nas vilas e na cidade de São Paulo, antes dos primeiros anos do século XIX.

As pesquisas que fizemos nos livros de batismo do Arquivo da Cúria Metropolitana de São Paulo, embora nos tenhamos limitado à Paróquia da Sé, confirmaram as afirmações de Taunay sobre a espantosa quantidade de expostos crescente desde a segunda metade do século XVIII (10) . No periodo, que vai de 1800 a 1884, constatamos cifras impressionantes relativas ao número de crianças expostas e ilegítimas.

Até 1824, data da instalação da Roda da Santa Casa, registros de batismo revelam que os expostos em casas de particulares oscilam numa proporção de $17 \%$ a $25 \%$ dos totais. A partir dessa data, embora as "exposições" estejam divididas entre as casas particulares e Santa Casa, a proporção mencionada mantem-se, só diminuido, lentamente a partir de 1840 até atingir mais ou menos $1 / 10$ por volta de 1850 , para depois cair cada vez mais até se tornar pouco significativa no fim do século. Essa diminuição da porcentagem de expostos foi compensada pelo aumento do número dos "naturais" (ou ilegítimos) que só declinou depois de 1874. E provavel que a melhoria das condições econômicas tenha levado muitas mães a assumirem a responsabilidade da criação de seus filhos ilegítimos. Para melhor compreensão do que acabamos de afirmar elaboramos uma tabela que resume as cifras de nascimentos legítimos, naturais, e expostos, do período de 1800-1884, baseada nos dados dos Livros de Batismo de Livres e Libertos da Paróquia da Sé.

TABELA $A$.

QUADRO APROXIMADO DAS PORCENTAGENS DOS BATIZADOS DE LEGITIMOS, NATURAIS E EXPOSTOS NA PAROQUIA DA SE.

$\begin{array}{cccc}\text { ANOS } & \begin{array}{c}\text { LEGITIMOS } \\ (\%)\end{array} & \begin{array}{c}\text { NATURAIS } \\ (\%)\end{array} & \begin{array}{c}\text { EXPOSTOS } \\ (\%)\end{array} \\ 1800-1805 & 53 \text { a } 59 & 22 \text { a } 27 & 17 \text { a } 20 \\ 1806-1810 & 48 \text { a } 56 & 23 \text { a } 30 & 17 \text { a } 24 \\ 1811-1815 & 45 \text { a } 52 & 28 \text { a } 31 & 17 \text { a } 25 \\ 1816-1820 & 46 \text { a } 50 & 28 \text { a } 32 & 17 \text { a } 25 \\ 1821-1825 & 46 \text { a } 60 & 24 \text { a } 37 & 14 \text { a } 18 \\ 1826-1830 & 45 \text { a } 57 & 22 \text { a } 36 & 16 \text { a } 20 \\ 1831-1835 & 48 \text { a } 60 & 30 \text { a } 37 & 10 \text { a } 19\end{array}$

(10). - Taunay (Affonso de E.), História da Cidade de São Paulo no século XVIII. 1735-1765, vol. I - 2a. parte, págs. 107 e 136. Coleção do Departamento de Cultura, São Paulo, 1949. 


$\begin{array}{rrrrrrr}1836-1840 & 47 \text { a } 57 & 27 \text { a } 35 & 10 \text { a } & 21 \\ 1841-1845 & 44 \text { a } 52 & 36 \text { a } 40 & 10 \text { a } 18 \\ 1846-1850 & 48 \text { a } 52 & 32 \text { a } 41 & 8 \text { a } & 12 \\ 1851-1855 & 53 \text { a } 62 & 31 \text { a } 39 & 7 \text { a } & 8 \\ 1856-1860 & 50 \text { a } 56 & 37 \text { a } 45 & 4 \text { a } & 7 \\ 1861-1865 & 56 \text { a } 60 & 34 \text { a } 41 & 2,5 \text { a } & 6 \\ 1866-1870 & 58 \text { a } 64 & 32 \text { a } 38 & 2 \text { a } & 4 \\ 1871-1875 & 52 \text { a } 66 & 31 \text { a } 43 & 2,5 \text { a } & 4 \\ 1876-1880 & 60 \text { a } 68 & 28 \text { a } 36 & 2 \text { a } & 4 \\ 1881-1885 & 65 \text { a } 75 & 24 \text { a } 32 & 1 \text { a } & 4,5\end{array}$

Antes do exame do funcionamento da "roda" da Santa Casa é preciso procurar as causas desse grande número de expostos em São Paulo, semelhante aliás, ao de outras partes do Brasil.

\section{3. - A ORIGEM SOCIAL E RACIAL DOS EXPOSTOS. CON- SIDERAÇÕES E PROPOSITO.}

O que levaria as mães ou pais a "exporem" seus filhos à caridade pública o uparticular? Por que não os criavam do mesmo modo que o faziam as mães, ou pais, dos que encontramos registrados como "naturais" e que ultrapassam em proporção aos expostos?

Tudo o que é possivel aventar nesse terreno são conjecturas, porque mais uma vez, os documentos oficiais, assim como os da Misericórdia silenciam a respeito. Somente por referências indiretas a problemas como: a dificuldade dos casamentos, aos costumes e à moral e à situação econômica, social e cultural de São Paulo é que podemos deduzir algumas causas para o problema proposto, que passamos a expor.

Em primeiro lugar, as mães dos expostos deviam ser mulheres livres porque para uma escrava seria dificil ocultar sua condição de gestante assim como o filho, que, pela lei pertencia ao seu proprietário, natural interessado na criança.

Mais, dificilmente ainda seria uma mulher branca da classe dominante, dos grandes proprietários, mesmo dos seus membros empobrecidos, porque esta era ciumentamente enclausurada pelo orgulho familiar de manter a pureza de sangue dos velhos clãs patriarcais. Assim como para as escravas, era dificil para elas ocultar qualquer deslize contra a moral vigente, a menos que, por prodígios de fidelidade dos que a rodeavam conseguisse dissimular a gravidez durante alguma longa ausência de maridos, pais ou irmãos. 
Restam, portanto, as mulheres livres, brancas, pardas ou negras forras, sem condição social definida e sem família para protege-las, as quais acreditamos formam o maior contingente das mães dos expostos. O fato de que as Atas de batismo, raríssimas vezes definam a cor das crianças, a menos que fossem escravas, nos impede de saber se as mães responsáveis pelas exposições eram brancas, negras ou mestiças.

Para o caso de Salvador, Russell-Wood concluiu que as negras expunham menos os filhos devido a razões sociais e culturais que ele explica da seguinte maneira:

"They were not so subject to social prejudices as their white counterpart in a correspondingly modest position. An illegitimate child did not dishonour the mother to the same extent as a white woman. Whenever financial means would permit, the illegitimate child was brought up as a one of the family. A visitor to modern Bahia cannot fail to notice the ease with which coloured families absorb another child, be an illegitimate or the child of a dead neighbour or relation. Somehow there is always room for yet another child. The Negro seems to regard the family as a more flexible unit than the white man. Financial considerations are not given such preeminence provided that the family can manage to escape starvation. This attitude towards the child cannot have been so different in colonial Brazil and may explain why so few colored were placed in the turning wheel" (11).

Acreditamos que o mesmo se aplica a São Paulo, porque para os inúmeros filhos naturais registrados nos livros de batismo da Sé, a grande maioria das mães assinaladas é constituida de mulheres pardas ou negras forras.

Por esse processo de eliminação chegamos, portanto, ao grupo que consideramos o mais provavel, ou seja o das brancas ou mestiças livres e pobres. A única informação oficial que temos sobre a cor dos expostos de São Paulo é a do Visconde de Congonhas do Campo, em 1825, que afirma serem, na maioria, brancos (12) .

Os recenseamentos da capitania de São Paulo iniciados na segunda metade do século XVIII, revelam um excesso do número de mulheres sobre o de homens, fato que se explica pela mobilidade dos mesmos em

(11). - Russel-Wood (A. J. R.), Fidalgos and Philanthropists - the Santa Casa de Misericordia of Bahia 1550-1755. University of California Press. Berkeley and Los Angeles, 1968, pág. 314.

(12) - "Relatório da Província de São Paulo pelo Ilmo. e Exmo. Sr. Luís Antônio Monteiro de Barros... e atual Presidente desta Província de São Paulo" in Boletim do Departamento Estadual de Estatistica n' ${ }^{\circ}$, São Paulo, fevereiro, 1939, pág. 37. 
busca de meio de vida no comércio com outras capitanias com as tropas de mulas. A cidade de São Paulo, situada em área pouco propícia à lavoura do açucar, a mais atraente da época, funcionou sobretudo como eixo de um sistema de comunicações que ligava o Sul com o Rio de Janeiro e as regiōes de Mato Grosso, Goiás e Minas Gerais, através do comércio. Alem do mais a cidade abrigava tropas militares aqui estacionadas desde as últimas décadas do século XVIII com objetivo de defender o Sul contra os castelhanos. Se somarmos aos tropeiros e soldados, os clérigos e funcionários e, depois de 1827, os estudantes da Academia de Direito, teremos em São Paulo uma consideravel população masculina de carater mais ou menos flutuante, muitas vezes sem vida familiar organizada que devia atrair e sustentar um apreciavel número de mulheres que viviam da prostituição ou semi-prostituição. Saint-Hilaire, no início do século XIX, ao descrever São Paulo horrorizava-se com seu número e dizia:

"Em nenhuma parte do mundo por mim percorrida vi tamanho número de prostitutas; eram de todas as cores; as calçadas ficavam, por assim dizer cobertas de mulheres dessa baixa espécie" (13).

\section{O que explicaria esse grande número de prostitutas?}

Já nos referimos a exploração sexual da mulher de cor, índia ou negra, pelo branco proprietário, propiciada e admitida pela escravidão, e que foi responsavel pela multidão de bastardos. Mesmo quando livre, a mulher mestiça ou de cor não escapava dessa degradante exploração uma vez que os costumes só a aceitavam como concubina temporária, numa união cuja duração dependia tão somente do capricho do homem. Embora os cronistas da época se refiram ao desprezo das esposas legítimas em favor dessas concubinas (14), assim como a relutância pelo casamento por parte dos celibatários, não acreditamos que esses costumes resultassem em uniões definitivas com as mulheres de classe inferior ou de segurança para sua prole.

Mesmo os casamentos com homens pobres eram desencorajados pelas dificuldades burocráticas e o alto preço das dispensas eclesiásticas, conforme já lembrava o Morgado de Mateus (15), que comentava ainda a "preguiça" dos naturais da colônia .

(13). - Saint-Hilaire (Auguste de), Viagem a São Paulo. Companhia Editora Nacional. São Paulo, s. d., pág.

(14). - Fonseca (Pe. Manuel da), Vida do Veneravel padre Belchior de Pontes da Companhia de Jesus da Província do Brasil. Companhia Melhoramentos de São Paulo, s. d., pág. 77.

(15). - Documentos Interessantes, vol. XXIII, págs. 380 e 381. 
O próprio Morgado já explicava, talvez sem perceber, as verdadeiras causas dessa "preguiça" quando se queixava do abandono que sofrera pelos seus criados, que, ao chegar da Metrópole, preferiam passar fome a trabalhar em atividades que os equiparassem aos negros (16).

Era a mancha do trabalho manual ou "mecânico", que já em Portugal excluia os homens dos privilégios políticos e civis, e que na Colônia se agravara com o sistema escravocrata. No Brasil, alem de incompatibiliza-lo com o direito de participar do governo das câmaras municipais, o homem branco perdia seu status e dignidade do homem livre se exercesse trabalho reservado aos escravos. Dentre as inúmeras referências a esse problema, escolhemos a de Vilhena, que a nosso ver conseguiu melhor definir para o período colonial a mentalidade do homem livre não-proprietário, assim como o das mulheres, no que se refere ao trabalho:

"Observa-se que o que aqui vem servindo algum ministro hé só bom criado enquanto não reflete que elle em caza de seu amo se emprega naquelle serviço que nas outras só são da repartição dos negros e povos mulatos, motivo porque começa a perseguir logo o amo para que o acomode em algum emprego público que não seja da repartição dos negros e tão publicamente os empregão alguns amos, que se veem perseguidos e mal servidos que os poem no meyo da rua: se porem os amos se demorão em dar este despacho, os criados se antecipão, tendo por melhor sorte o ser vadio, o andar morrendo de fome, o vir parar em soldado e as vêzes em ladrão do que servir hum amo honrado que lhes paga bem, que os sustenta, os estima, e isto por não fazerem o que os negros fazem em outras casas.

Igual hé a sorte das creadas que de Portugal vem acompanhando as senhoras, as quaes, pela mesma preocupação se poem, ou as poem na rua, querendo antes sujeitar-se às consequências da triste mizeria do que viver recolhidas em huma caza que as honra e as ampara.

As filhas do Paiz tem um timbre tal que a filha do homem mais pobre, do mais abjecto, a mais desamparada mulatinha fôrra, com mais facilidade hirão ao patíbulo do que a servir a huma Duqueza, se na terra as houvesse; e este hé o motivo porque se achão nesta cidade tantas mulheres perdidas e desgrasadas" (17).

(16). - Documentos Interessantes, vol. XXIII, págs. 253, 379 e 380.

(17). - Vilhena (Luis dos Santos), Recopilação de Notícias Soteropolitanas e Brasilicas. Imprensa Oficial do Estado. Bahia, 1921, vol. I, pág. 140. 
Eis aí o retrato esboçado da realidade sócio-cultural, tal como foi surpreendida por Vilhena, em fins do século XVIII, que se soma a outros ao identificar como causa básica do problema o. sistema escravocrata, que, alem de não dar oportunidade ao trabalho livre ainda o degradava com a imposição dos seus valores "aristocratizantes" de ideal de vida ociosa e nobre.

Saint-Hilaire, ao visitar São Paulo, constatou, como já vimos, a existência de inúmeras prostitutas e identificou os motivos econômico-sociais do fato ao dizer:

"As mulheres ricas, informaram-me trabalham em leves serviços no interior de suas casas - bordam, fazem flores, enquanto que um grande número de mulheres pobres permanecem em ociosidade durante o dia, e, quando a noite, espalham-se pela cidade, dedicando-se, ao tráfico de seus encantos, como único recurso de subsistência" (18).

Se na sociedade escravocrata os homens livres não encontravam trabalho, porque até as atividades artesanais nas cidades estavam entregues aos "escravos de ganho", a situação das mulheres era ainda pior, uma vez que não se admitia que trabalhassem fora de suas casas. A falta de estudos a respeito da organização do trabalho livre em geral, e do feminino, em particular, nos impedem de fazer afirmações definitivas a respeito do problema, mas lembraremos que quando Debret retrata os tipos humanos do Rio de Janeiro encontramos ali as famosas negras "quitandeiras" ou padeiras que, livres ou escravas, parecem representar as únicas profissões femininas da época (19). A este quadro acrescentaríamos no caso da cidade de São Paulo, a existência de costureiras, em número crescente a partir de 1776 (20) e em outras localidades as tecelãs que ocuparam consideravel mão-de-obra feminina (21).

É nesse quadro sócio-econômico e cultural que devemos compreender o problema do grande número dos expostos na cidade de São Paulo que no início do século XIX suscitou preocupação nas consciências mais sensíveis e as primeiras medidas para soluciona-lo.

(18). - Saint-Hileire (Auguste de), op. cit.

(19). - Debret (Jean Baptiste), Viagem Pitoresca e Histórica ao Brasil. Livraria Martins, São Paulo, 1940. Tomo I, pág. 215, prancha 32.

(20) . - Marcílio (Maria Luiza), La Ville de São Paulo - Peuplement et Population. 1750-1850. Publications de l'Université de Rouen, 1968, pág. 153.

(21). - Hermann (Lucilla), op. cit., pág. 72. 
4. - A INSTALAÇÃo DA "RODA" EM SÃo PAULO. A SANTA CASA E A POLEMICA SOBRE AS RESPONSABILIDADES DO MUNICIPIO.

Embora existam, no período relativo ao século XVIII, inúmeras referências a bastardos e engeitados a evidência documental permite-nos afirmar que nenhuma medida efetiva teria sido tomada em seu favor, uma vez que a sua absorção precária pela sociedade estava garantida graças ao exposto no início deste artigo.

Outros fatores a considerar seriam a pobreza geral da cidade e da capitania, assim como a falta de espírito cívico que levasse os habitantes a se congregarem em busca de uma solução comunitária para problema até então entregue à caridade particular.

Mas o ponto de saturação já se aproximava, conforme se pode deduzir pela crítica de Rendon que em suas Reflexões sobre o estado em que se acha a agricultura na capitania de São Paulo (22), por volta de 1788, alertava quanto ao grande número de mendigos de ambos sexos que aí pululavam. Lembrava, pela primeira vez, a necessidade de criar alguma instituição que encaminhasse e profissionalizasse os bastardos diminuindo assim a criminalidade e a prostituição que tanto prejudicavam o povoamento.

As Reflexões de Rendon são um interessante exemplo da consideravel literatura que, sob a forma de Memórias e Cartas, surgiu na Colônia visando alertar as autoridades sobre as questões de desenvolvimento e povoamento.

Variavam na ênfase dada às causas das dificuldades da economia colonial e nas soluções que propunham mas a maioria concorda ao assinalar o grave problema da falta de elemento humano para um território vastíssimo e desaproveitado. Paradoxalmente constatam ainda a existência de uma consideravel camada da população que vivia em condições de ociosidade e marginalização.

E nesse contexto que devemos encarar as tentativas que surgem no início do século XIX com vistas ao abrigo e encaminhamento dos expostos pondo fim, desta forma, ao criminoso desperdício humano e econômico que representava o seu abandôno.

Até 1824 eram as crianças indesejáveis de São Paulo expostas nas portas das casas particulares, nos lugares de frequência pública como igrejas e ruas ou simplesmente atiradas em monturos de lixo! O lugar

(22). - Rendon (Mal. José Arouche de Toledo), Reflexões sobre o estado em que se acha a agricultura na capitania de São Paulo, in "Documentos Interessartes para História e Costumes de São Paulo", vol. 44. Diversos. São Paulo, 1915. 
preferido pelas mães ou parteiras era a casa dos parentes (e até dos próprios pais) e de particulares conhecidos pela sua caridade. Muitas vezes quando abandonados à porta dos pais estes recolhiam os expostos, batizando-os para cria-los na qualidade de "padrinhos" ou "madrinhas".

Os livros de batismo da Paróquia da Sé revelam esse artifício, quando, mais tarde, essas crianças eram reconhecidas por um dos pais ou legitimadas pelo casamento de ambos.

Muitas personalidades da antiga história de São Paulo expuzeram seus filhos ou foram eles próprios expostos e lembraremos aqui os dois exemplos máis ilustres - o da Marquesa de Santos (22a.) e do Pe. Diogo Antônio Feijó (23).

Mas acontecia, muitas vezes, que as crianças não eram recolhidas, ou então, mães ou parteiras irresponsáveis as atiravom em monturos de lixo, e, nesse caso, acabavam sendo devoradas por cães ou porcos.

O primeiro a revelar interesse por esses infelizes inocentes foi o quarto bispo de São Paulo, D. Mateus de Abreu Pereira, que residindo

"na antiga casa de sobrado, de sacadas de rótula, situada à rua do Carmo $\mathrm{n}^{\circ} 20$, sendo que, em frente à mesma casa deste prelado existia um cisqueiro e matos, onde era ahi costume enjeitarem crianças... logo que houvia choro de qualquer delas no mesmo lugar, que ficava na esquina da rua e ladeira do Carmo... se apressava em mandar o seu criado busca-las e, da janela, batisava a mesma criança, receando que os porcos ou outros animais, que por ali andavam, a devorassem antes da chegada do mesmo criado" (24).

Não sabemos que destino dava o bispo às crianças recolhidas. Provavelmente entregava-as a particulares que as criassem.

Embora já existissem as "rodas" e todo um sistema de amparo aos expostos em Salvador (25) e no Rio de Janeiro (26) desde o sé-

(22a.). - Trata-se de D. Maria Alcântara Brasileira, nascida a 28 de fevereiro de 1830 e batizada a 24 de maio de 1831 com declaração de que fora exposta na casa da Viscondessa de Castro. In Livro n' 13 - "Batizados de Brancos e Libertos 1829-1849" - 3-1-29. Arquivo da Cúria Metropolitana de São Paulo.

(23). - Sousa (Octavio Tarquínio de), História dos Fundadores do Império do Brasil. Vol. VII. Diogo Antônio Feijó. Livraria José Olímpio Editora. Rio de Janeiro, 1960, pág. 11.

(24). - Martins (Antônio Egídio), São Paulo Antigo, pág. 82.

(25). - Russell-Wood, op. cit., pág. 295 a 319.

(26). - Soares (Ubaldo), $O$ passado heróico da Casa dos Expostos. Rio de Janeiro, 1959, pág. 21. 
culo XVIII, em São Paulo nem a Câmara Municipal nem a Santa Casa tomaram qualquer medida nesse sentido embora a legislação portuguesa lhes atribuisse essa responsabilidade.

O Alvará de 1806, que, conforme já vimos, regulamentou as Misericórdias de todo Império português, dedicou em diversos artigos especial atenção aos expostos. Pelo artigo VII, ficava determinado que, mesmo nos lugares onde a criação dos expostos pertencia aos concelhos, as Misericórdias teriam função fiscalizadora. Pelos artigos IX e X ficou estabelecido que as instituições que criassem expostos deveriam manter a Roda confirmando, ainda, os privilégios concedidos pela coroa aos que os educassem (27) .

Parece não existirem medidas, ou mesmo propostas da Câmara Municipal de São Paulo no sentido de se criar a "roda" ou qualquer tipo de assistência aos expostos, antes ou depois do Alvará de 1806.

A Santa Casa, no entanto, já se preocupava com a questão, conforme permitem concluir algumas referências documentais esparsas, que suprem a lacuna decorrente do desaparecimento do Livro de Atas no 2 dos Termos de Mesa.

Em 1810, quando Franca e Horta ainda era Governador da capitania e Provedor da Santa Casa, sua esposa D. Luiza Catharina Xiber (ou Chibert?) de Horta dirigia uma petição ao Príncipe Regente, solicitando a aplicação do patrimônio representado pela Fazenda de Santana e seus escravos para o estabelecimento de uma Roda (28). Nessa petição D. Luiza argumentava alegando a necessidade daquela instituição, dado o grande número dos que pereciam sem socorro e ressaltava os grandes serviços de seu marido no campo da assistência social com o apôio que conferiu às Misericórdias da capitania. Outro requerimento da mesma senhora, provavelmente no ano seguinte, porque ainda alegava ser esposa do Governador, pedia decisão urgente sobre a questão da Fazenda de Santana, sequestrada aos jesuitas, uma vez que a Junta da Fazenda de São Paulo já se pronunciara favoravelmente e para

"se salvarem tantas vidas quantas todos os dias se veem aparecer (ou perecer?) naquela Cidade, por falta de hum socorro" (29).

(27). - Colleç̧ão de Legislação Portugueza desde a última compilação das Ordenações, redigida pelo desembargador Antônio Delgado da Silva. Vol. $\mathrm{E}$, de 1802-1810, Lisboa, 1926.

(28) . - Arquivo do Museu Imperial - Divisão de Documentação Histórica II-POB; S/D; JVI. P. pe.; 23-25.

(29). - Registro Geral da Câmara Municipal de São Paulo 1803-1808, vol. XIII, pág. 329. Em carta ao Governador Horta a Câmara assim, pito- 
A substituição de Franca e Horta, em 1811, com certeza, explica o abandono e o esquecimento do projeto que empreendera com sua energia característica em tais casos.

Mas a Irmandade da Santa Casa não esqueceria o projeto da Roda que complementava o de um Hospital de Caridade, conforme se deduz de petição enviada ao imperador em 1824, pela Mesa na provedoria do Mal. Presidente do governo, Candido Xavier de Almeida e Souza (30). Nessa petição que solicitava a nomeação de esmoleres, alegava a Irmandade que não podia construir o Hospital e a Roda, conforme almejava, porque seus recursos eram insuficientes até para os Lázaros e para as "diárias" dos indigentes que tratava no Hospital Militar.

Nesse mesmo ano a Santa Casa iniciou um processo de grandes transformações, sob a liderança do primeiro Presidente da Província Lucas Antônio Monteiro de Barros, Visconde de Congonhas do Campo.

Adquirida a "Chácara dos Ingleses" com os recursos do legado do Cons. Diogo de Toledo Lara Ordonhez foram ali inaugurados, a 2 de julho de 1825, o Hospital de Caridade e a Roda dos expostos (31).

Nas sucessivas mudanças do Hospital da Santa Casa, a Roda sempre o acompanhou, desaparecendo somente em 1950, conforme noticiava reportagem de jornal desta capital, ressaltando que a de São Paulo era a última do Brasil! (32).

Monteiro de Barros e seus sucessores na provedoria da Irmandade esforçaram-se por conseguir da Câmara Municipal de São Paulo uma quota anual para a criação dos expostos baseando-se nos Alvarás de 1775 e 1783 que regulamentavam a matéria. Monteiro de Barros conseguiu a aprovação do Conselho da Província para sua proposta para que a Câmara destinasse a 8a. parte de suas rendas conforme determinavam as Ordenações do Reino Lọ 19, título 88, § 11 (33).

rescamente, o cumprimentava pela breve chegada da esposa em 4-9-1905:... "que o céu queira abençoar suavisando com a deliciosa posse de uma tão digna consorte como a ilustrissima e excelentissima senhora Dona Luiza Catharina Ghibert de Miranda que a qualquer hora é provavel esteja a surgir nesse porto; pois que estando nós iá em setembro e por conseguinte no principio da doce volta da estação das flores é muito natural appareça a reanimar, as delicias da Horta um candido lyrio de França".

(30). - Doc. 48 - Cx. 364 - Correspondência dos governadores de São Paulo com o Ministro do Império - Arquivo Nacional do Rio de Janeiro. (31). - Martins de Almeida (Francisco), Primeiro Relatório sobre a Santa Casa de Misericórdia da Cidade de São Paulo. Typ. de Jorge Seckler. São Paulo, 2a. edição, 1909, pág. 23.

(32). - A Gazeta de 14 de janeiro de 1950, São Paulo.

(33). - Documentos Interessantes, vol. 86 "Atas do Conselho da Província da Presidência da Província de São Paulo, anos de 1824-1829" pág. 66. 
A Câmara recusou alegando falta de recursos e de poderes ao Conselho Provincial para determinar essa aplicação de rendas (34). E apelou ainda, em consulta ao Desembargo do Paço que respondeu aprovando a decisão do Conselho de Província dizendo:

... "porquanto o cuidado da criação dos expostos é um dever social que foi incumbido a todas as Câmaras, debaixo da vigia dos corregedores e provedores desde o ano de 1783 , de que se faz menção no $\S 7^{\circ}$ do Alvará de 18-10-1806..." (35).

Diante desse pronunciamento taxativo a Câmara submeteu-se e passou a contribuir para a criação dos Expostos com pequenas quantias em 1827 (36), 1828 (37) e 1829 (38) mas, no início de 1830, consultou novamente o Conselho de Província a respeito, alegando as reformas introduzidas pela Lei dos Municípios de 1 de outubro de 1828 (39) .

A referida Lei nos artigos 69 e 70, do Título III - Posturas Policiais previa que as Câmaras deviam criar, conservar ou amparar as casas de caridade que criassem expostos, e curassem os doentes; e no artigo 76 do Título IV - Aplicação de rendas - recomendava:

"Não podendo prover a todos os objetos de suas atribuições, preferirão aqueles que forem mais urgentes, e nas cidades ou vilas, aonde não houverem casas de Misericórdia, atentarão principalmente na criação dos expostos, sua educação e os mais órfãos pobres e desamparądos" (40).

Embora, mais uma vez, o Conselho de Província se tivesse pronunciado a favor da Santa Casa, a falta de informações posteriores sobre qualquer pagamento de quota para os expostos permite concluir

(34) . - "Registro Geral da Câmara Municipal de São Paulo 1826-1828", vol. XIX, pág. 39 .

(35). - "Colleç̧ão das Decisões do governo do Imperio do Brazil de 1826, Rio de Janeiro, 1881, pág. 137. "Provisão da Mesa do Desembargo do Paço de 4 de novembro de 1826".

(36). - Atas da Câmara Municipal de São Paulo 1826-1829, vol. XXIV, pág. 66 - Vereança de 17 de março de 1827.

(37). - Idem acima, pág. 138 - Vereança de 12 de janeiro de 1828.

(38). - Idem acima, pág. 269 - Sessão de 14 de fevereiro de 1829.

(39). - Registro Geral da Câmara Municipal de São Paulo 1829-1830, vol. XX, pág. 238-9.

(40). -Leis do Império do Brasil 1829 - Atos do Poder Legislativo Império Lei de $1^{\circ}$ de outubro de 1828 , pág. 25. 
que a redação dúbia da Lei de 1828 , forneceu argumentos à Câmara para se eximir dessa despesa (41).

\section{5. - O SISTEMA ASSISTENCIAL DA RODA.}

E bastante dificil reconstituir o modo segundo o qual eram tratadas as crianças expostas na Roda, devido ao desaparecimento dos respectivos Livros de Entrada, assim como, pela inexistência de um Regimento que regulamentasse a vida da instituição, fato que já Martins de Almeida assinalava dizendo

"Ignoro como se havia a Santa Casa com esses orfãos" (42).

O artigo 14 do Compromisso de 1836 instituiu o Mordomo dos Expostos que tornou-se o responsavel direto pelo funcionamento do sistema da Roda, encarregado de providenciar sobre tudo que se referia às crianças abandonadas.

No entanto, em 1828, por ocasião da elaboração do Compromisso e do Regimento do Hospital de Caridade, foi tambem organizado um para os Expostos que, como os outros, não foi aprovado (43). Apesar disso partes do mesmo parecem ter sido aproveitadas, conforme se pode verificar pelo funcionamento posterior da Roda, tal como se delineia nos termos de Mesa da Irmandade. Assim os art. $60^{\circ}$ do cap. $2^{9}$ e o art. $4^{\circ}$ do cap. $3^{\circ}$ previam a existência de um Livro de Matrícula dos expostos e de uma regente que deveria anotar no referido diário a data, a hora e todos os característicos possíveis da criança lançada na Roda para qualquer identificação futura (44).

Essa regente que, nas Atas surge com o nome de Zeladora dos expostos, e recebia, em 1841, a quantia de $4 \$ 000$ mensais (45), estava encarregada de cuidar das crianças até que fossem entregues às amas.

(41). - Registro Geral da Câmara Municipal de São Paulo 1829-1830, vol. XX, pág. 326. Ofício do secretário do Conselho Geral à Câmara, sobre a 8a. parte das rendas a benefício da Santa Casa lido a 16 de abril de 1830 (datado de 8-2-1830).

(42). - Martins de Almeida, op. cit., pág. 25.

(43). - Regimento para a Casa dos Expostos da Imperial Cidade de São Paulo, Doc. 10, cx. 364. Correspondência dos governadores de São Paulo com o Ministro do Império 12828. Arquivo Nacional do Rio de Janeiro.

(44). - Idem acima.

(45). - Termo de Mesa de 19-3-1841. Livro de Atas n III, fl. 93. 
a). - As amas.

Instalada a Roda, o Provedor, e Presidente da Província Visconde de Congonhas do Campo, enviou cartas aos capitães das diversas freguesias pedindo listas do possiveis amas, ao que, o Cap. Manoel José da Silva, de Pinheiros, respondeu não haver ali índias adequadas (46) . O comandante Eleutério da Silva Prado informou que havia 18 em Cotia, 17 em São Bernardo, 27 em Nossa Senhora do 0, 4 em Penha de França e 56 em Santo Amaro (47).

A zona de Santo Amaro, onde viviam muitas índias, era a freguesia que mais amas fornecia a Santa Casa, agenciadas pelo Sr. Vicente Antônio Borba, ao qual a Mesa agradeceu em 1867 (48).

$\mathrm{Na}$ mesma ocasião foi tambem homenageado o Sr. Adolfo Pinheiro e Prado que tratava dos expostos fornecendo-lhes remédios.

Em 1871 a Mesa agradecia o mesmo serviço ao Sr. Adolfo Alves Pinheiro e Paiva, que julgamos ser o mesmo da ocasião anterior, ficando a diferença no nome por conta de alguma confusão na redação das atas (49).

Na Misericórdia de São Paulo não encontramos traços de um costume vigente no Rio de Janeiro, onde pessoas de renome costumavam alugar suas escravas para servirem de amas. O autor de estudo sobre os expostos do Rio de Janeiro conclui que os proventos desse aluguel não eram embolsados pelos donos, mas serviriam para a alforria das escravas. Todavia não apresenta qualquer prova documental que confirme tal asserção (50).

Os salários das amas em São Paulo eram, obviamente muito mais baixos do que no Rio de Janeiro (51). Recebiam as "de leite", $3 \$ 000$ e as "secas" $2 \$ 000$ em 1854 (52). Foram aumentadas respectivamente para $5 \$ 000$ e $4 \$ 000$ em 1863 (53).

Alem destas amas externas, havia sempre uma ou duas no hospital para as emergência, as quais recebiam em 1831 (54) $1 \$ 920$ mensais e $3 \$ 200 \mathrm{em} 1835$ (55).

(46). - I-I-R: Santa Casa de Misericórdia - Diversas Localidades Anos 1824-1891 - Arquivo do Estado de São Paulo.

(47). - Idem acima.

(48). - Termo de Mesa de 7-7-1867 - Livro de Atas no 4, fl. 41 v.

(49). - Termo de Mesa de 25-6-1871. Livro de Atas n 4, fl. 66 v.

(50). - Soares (Ubaldo, op. cit., pág. 47.

(51). - Idem acima, pág. 48. Em 1854 ganhavam $28 \$ 000$ mensais.

(52). - Termo de Mesa de 5-2-1854. Livro de Atas n 3, fl. 141.

(53). - Termo de Mesa de 5-7-1863. Livro de Atas $n^{\circ} 4$, fl. 11. 
Aos expostos cabia um enxoval quando entregues às amas. Recebiam outro, anualmente, no dia da Visitação ao serem levados ao Hospital para apresentação à Mesa e ao público .

Em caso de maus tratos os expostos eram recolhidos pelo Mordomo conforme aconteceu em 1844 (56).

\section{b). - $O$ encaminhamento posterior dos Expostos.}

Os expostos ficavam sob os cuidados da Misericórdia até os 7 anos quando eram colocados nos Seminários da Glória para meninas e de Santana para meninos onde permaneciam até se empregarem os rapazes ou casarem as moças (57).

O_Seminário da Glória foi criado por proposta do presidente da Província, Visconde de Congonhas do Campo, em 1824, para servir de internato para as meninas orfãs, especialmente de militares, com dotação anual de $600 \$ 000$. Foi instalado na Chácara da Glória, que era próprio da Fazenda Nacional desde 1792, tendo mudado por diversas vezes para outros locais. Em 1847, foi criada, anexa ao Seminário, uma Escola Normal, só instalada em 1852 e suprimida em 1856. O nivel da educação só melhorou em 1870 quando a direção do estabelecimento foi confiada à congregação das Irmãs de São José (58).

O Seminário de Santana, instalado na Fazenda de Santana, sequestrada aos jesuitas, para educação dos meninos teve vida ainda mais precária, somente sofrendo verdadeira reforma em 1874 com a criação do Instituto de Artífices (59).

Quando atingiam aquela idade a Mesa oficiava ao presidente da Província pedindo a sua aceitação nos Seminários o que nem sempre era atendido por falta de vagas. Revelam os relatórios das Comissões de Visitas da Câmara Municipal, até 1841, com toda crueza a precariedade desses estabelecimentos, que não eram meros asilos, mas até se propunham a educar alunos pensionistas. Alem da alfabetização e algumas artes domésticas para as meninas, todavia muito pouco era ensinado que habilitasse as crianças a mais tarde ganharem a vida.

(54). - Termo de Mesa de 2-10-1831. Livro de Atas n? 3, fl. 23.

(55). - Termo de Mesa de 4-10-1835. Livro de Atas $\mathrm{n}^{\circ} 3, \mathrm{fl} .46$.

(56). - Termo de Mesa de 21-4-1844. Livro de Atas no 3, fl. 107 v.

(57). - Segundo $\S 3^{\circ}$ do Alvará de 31-1-1775 cuja observação foi suscitada pela Provisão de 22-2-1823.

(58). - Ferreira (Toltoi de Paula), Subsidios para a história da Assistência Social em São Paulo. Separata da "Revista do Arquivo Municipal" no LXVII - Departamento de Cultura, São Paulo, 1940, pág. 47 a 51. "Documentos Interessantes”, vol. 86, pág. 24.

(59). - Ferreira (Tolstoi de Paula), op. cit., pág. 55. 
Em 1845, cogitou-se de enviar os meninos expostos para o Arsenal de Marinha, o que foi feito com um certo Joaquim. Parece tratrar-se de caso isolado, que não se repetiu e, o que decorreria das ásperas condições da vida dos marinheiros na época (60).

Outro destino frequente dos expostos era a entrega aos seus primeiros criadores ou a quaisquer particulares, que se propusessem a educa-los, a ensinar-lhes um ofício ou a "dar-lhes estado" no caso das moças (61).

Não raro era o caso de pais ou mães (estas mais comumente) que reclamavam as crianças expostas no passado por circunstâncias as mais diversas.

Em 1831 era entregue a seu pai Antônio Joaquim da Silva, a pedido deste, o exposto Elias mediante o pagamento das despesas feitas com sua criação conforme era norma em tais casos (62). $\mathrm{O}$ mesmo aconteceu com a filha de um certo Joaquim Antônio, solteiro, de São Bernardo, que, nascendo durante sua ausência, fora exposta na Roda (63) .

Tambem as mães se arrependiam. E o caso de certa Maria da Cruz que, em 1839, pedia seu filho Antônio, lançado na Roda do dia 29-10-1836 (64). Em 1842 Maria Delfina da Fonseca requeria a entrega de sua filha Ana Maria, de 4 anos, que expusera por não poder cria-la mas que agora "estando melhor a pedia de volta" (65).

Caso comovente, e que suscita as mais diversas cogitações, é o do

"requerimento de Antônio, preto mina e sua mulher Generosa, creoula, escravos que forão do finado Barão de Limeira e hoje livres, pedindo a entrega de sua filha (que tem o nome de Marcelina) lançada na roda a 16 de abril de 1870 , para cujo acto em nada concorrerão so supplicantes, visto que nessa epoca ainda eram escravos".

O mordomo dos Expostos comunicou que provisoriamente entregara a menina a seus pais (66) .

Não encontramos referência na Santa Casa de São Paulo sobre o trágico problema de expostos negros, colocados na Roda do Rio de

(60). - Termo de Mesa de 6-4-1845. Livro de Atas n9 3, fl. $112 \mathrm{v}$.

(61). - Termo de Mesa de 3-11-1833. Livro de Atas no 3, fl. 34. v.

(62). - Termo de Mesa de 9-12-1831. Livro de Atas $\mathrm{n}^{\circ} 3$, fl. $24 \mathrm{v}$.

(63). - Termo de Mesa de 8-11-1835. Livro de Atas $\mathrm{n}^{\circ} 3$, fl. $47 \mathrm{v}$.

(64). - Termo de Mesa de 14-7-1839. Livro de Atas n' 3, fl. 84.

(65). - Termo de Mesa de 14-8-1842. Livro de Atas $\mathrm{n}^{\circ}$ 3, fl. $100 \mathrm{v}$.

(66). - Termo de Mesa de 5-7-1874. Livro de Atas n 4, fl. 90. 
Janeiro, com a declaração anônima de que seriam procurados depois, e pagas as despezas da sua criação, mas sem a confissão de que eram filhos de escravos. Seus cínicos senhores depois os procuravam, pagavam as despesas da criação e os reduziam à escravidão o que motivou uma representação do Mordomo dos Expostos ao Imperador, pedindo esclarecimento sobre o Alvará de 1775 que confirmasse sua liberdade o que foi feito por Provisão de 22-3-1823 (67).

A escravidão, instituição que tanto influenciou a mentalidade da época, desvirtuava, usando em seu proveito o ideal da Santa Casa da Misericórdia, entregando-lhe seus escravos doentes e inválidos tentou até livrar-se, através dela, da responsabilidade da criação das crianças escravas!

Quanto ao número dos expostos que entraram e sairam da Roda de 1824 a 1884 nada foi possivel descobrir devido ao desaparecimento (?) do mais importante documento para esse levantamento, a saber o Livro de Entradas dos mesmos, o que já era lamentado por Martins de Almeida, em 1875 (68). O mesmo autor apresenta no Anexo Y um quadro de expostos referente ao decênio 1864-1874 que comenta na página 49 concluindo que nesse período a Irmandade amparou 106 crianças; sendo 31 do sexo masculino e 66 do feminino dos quais teriam falecido $35,1 / 3$ do total!

Essa elevada mortalidade com certeza se explica pelos mesmos motivos apontados no Rio de Janeiro, onde anualmente, eram colocadas na Roda centenas de crianças mortas ou moribundas (69). Outro motivo para a mortalidade era a negligência das amas pobres e ignorantes, que viviam longe da cidade, onde nem sempre se encontrava um médico ou um farmacêutico como o já mencionado em Santo Amaro para socorrer as crianças.

Foi observando a precariedade dos cuidados dispensados aos expostos, que a Santa Casa, em data imprecisa, começou a reuni-los em dependência do Hospital sob a responsabilidade das Irmãs de Caridade dando início ao que mais tarde se transformaria verdadeiro orfanato com o Asilo Sampaio Viana em 1904.

O processo iniciou-se com a criação de uma escola para os expostos, por iniciativa da Irmã Superiora, apoiada pelo Irmão Capelão Arcipreste Dr. João Jacinto Gonçalves de Andrada com uma doação de 1:000\$000 em memória de seu tio Monsenhor Joaquim Manoel

(67). - Colleç̧ão das Decisões do Governo do Império do Brasil de 1823. Provisão da Mesa do Desembargo do Paço de 22 de fevereiro de 1823.

(68). - Martins de Almeida (Francisco de), op. cit., pág. 37.

(69). - Soares (Ubaldo), op. cit., pág. 34. De 1844 a 1888 foram lançadas 1529 crianças mortạs nạ Rodạ. 
Gonçalves (70). A escola instalada progrediu rapidamente e no mesmo ano de 1880 , em julho, já se aprovava a vinda de mais uma irmã para servir de professora (71).

Apesar das dificuldades financeiras desses anos em que se construia o novo Hospital, a escola continuou a crescer, formando o que futuramente viria a ser o Externato São José, transformado em estabelecimento de ensino de classe média.

O encaminhamento dos expostos para uma vida util tornou-se mais facil à medida que a Província se desenvolvia criando condições econômicas para sua sobrevivência. Mas o fator mais importante foi o fim do sistema escravocrata o que obrigou a aceitação social do trabalho livre, inclusive o feminino.

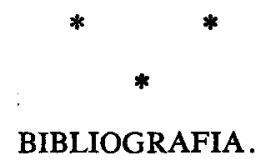

ALMEIDA (Francisco Martins de), Primeiro Relatório sobre a Santa Casa de Misericórdia da Cidade de São Paulo. Typ. de Jorge Seckler. São Paulo. $2^{\circ}$ ed. 1909.

CORREIA (Fernando da Silva), Origens e Formação das Misericórdias Portuguesas. Lisboa. 1944.

DEBRET (Jean Baptiste), Viagem Pitoresca e Histórica ao Brasil. Livraria Martins. São Paulo. 1940.

DUARTE (Nestor), A Ordem Privada e a Organização Política Nacional. Companhia Editora Nacional. São Paulo. 1939.

FERREIRA (Tolstoi de Paula), Subsídios para a História da Assistência Social em São Paulo, in "Revista do Arquivo Municipal", n' LXVII, São Paulo. 1940.

FONSECA (Pe. Manuel da), Vida do Veneravel Pe. Belchior de Pontes da Companhia de Jesus da Província do Brasil. Companhia Melhoramentos. São Paulo. s. d.

HERRMANN (Lucilla), Evolução da Estrutura Social de Guaratinguetá num período de trezentos anos, in "Revista de Administração", n" 5-6.

HOLANDA (Sérgio Buarque de), Movimentos da População em São Paulo no século XVII, separata do $\mathrm{n}^{\circ} 1$ da "Revista do Instituto de Estudos Brasileiros". São Paulo. 1966.

MARCÍlIo (Maria Luiza), La ville de S. Paulo. Peuplement et Population 1750-1850. Publication de L'Université de Rouen. 1968.

MARTINS (Antônio Egídio), São Paulo Antigo (1554-1910). Livraria Francisco Alves \& Cia.. Rio de Janeiro. 1911.

(70). - Termo de Mesa de 14-3-1880. Livro de Atas $\mathrm{n}^{9}$ 5, fl. 97.

(71). - Termode Mesa de 11-7-1880. Livro de Atas $n^{\circ}$ 6, fl. 2 v. 
NEYRON (R. P. Gustave), Histoire de la Charité. Editions Spes. Paris. 1927. PERES (Damião) (dir. de), Historia de Portugal. Portucalense Editora Ltda. Barcelos. MCMXXXII.

RENDON (Mal. José Arouche de Toledo), Reflexóes sobre o estado em que se acha a agricultura na capitania de São Paulo, in "Documentos Interessantes para a História e Costumes de São Paulo". Vol. 44. São Paulo. 1915.

RUSSELL-WOOD (A. J. R.), Fidalgos and Philanthropists. The Santa Casa da Misericordia of Bahia 1550-1755. University of California Press. Berkeley and Los Angeles. 1968.

SAINT-HILAIRE (Auguste de), Viagem à São Paulo. Companhia Editora Nacional. São Paulo.

SOUSA (Otávio Tarquínio de), História dos Fundadores do Império: Diogo Antonio Feijó. Livraria José Olímpio. Rio de Janeiro. 1960.

TAUNAY (Affonso de E.), História da Cidade de São Paulo no século XVIII1735-1765. Vol. I. São Paulo. 1949.

VIANA (Oliveira), Instituições Políticas Brasileiras. Livraria José Olímpio Editora. Rio de Janeiro. 1949.

VILHENA (Luis dos Santos), Recopilação de Notícias Soteropolitanas e Brasilicas. Imprensa Oficial do Estado. Bahia. 1921.

LAIMA MESGRAVIS. Professora Assistente-Doutora junto ao Departamento de História da Faculdade de Filosofia, Letras e Ciências Humanas da Universidade de São Paulo, desde 1965. Nascida em 12 de julho de 1934, em Nova Odessa, Estado de São Paulo, bacharelou-se e licenciou-se em História pela Universidade de São Paulo em 1964. Atuou no magistério secundário de 1965 a 1972 sendo professora efetiva por concurso. Colaborou em equipes que prepararam aulas para Curso de Madureza da Fundação Padre Anchieta - TV Educativa e que foram editadas pela Editora Abril; na preparação de livros didaticos da "Coleção Sérgio Buarque de Holanda" de História Geral e do Brasil para o ensino médio. Tem ainda diversas comunicações apresentadas a Congressos da Sociedade Brasileira para o Progresso das Ciências (SBPC) e Associação Nacional dos Professores Universitários de História (ANPUH). Em 1974 sua tese de doutoramento intitulada $A$ Santa Casa de Misericórdia de São Paulo, defendida em 1973 foi contemplada com o premio Governador do Estado conferido pelo Conselho Estadual de Cultura de São Paulo. 